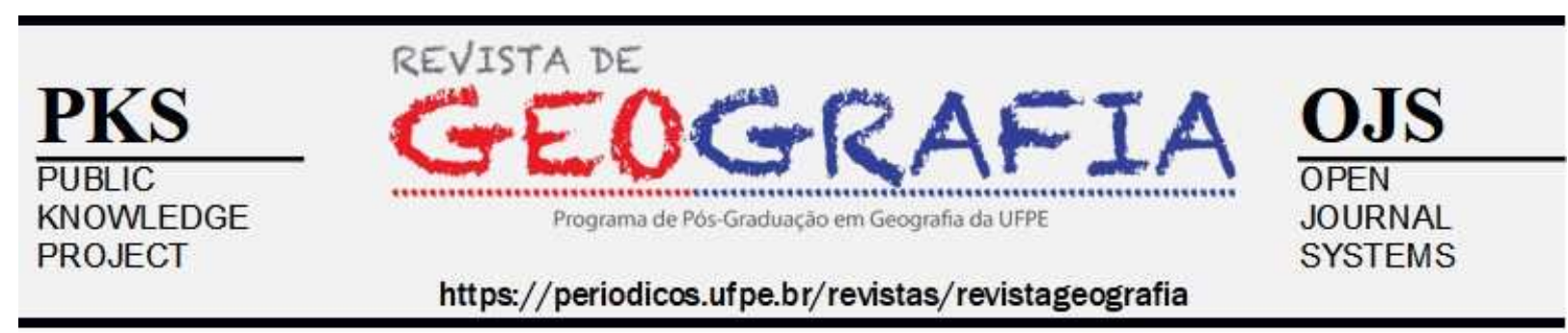

\title{
ANÁLISE DA LEGISLAÇÃO AMBIENTAL BRASILEIRA PARA PROTEÇÃO DAS VEREDAS
}

\author{
Eduardo Vieira dos Santos ${ }^{1}$, Frederico Augusto Guimarães Guilherme ${ }^{2}$, Renato Adriano \\ Martins $^{3}$, Kaila de Assis Ressel Pereira ${ }^{4}$
}

\begin{abstract}
${ }^{1}$ Universidade Federal de Mato Grosso, e-mail: edugeo2000@yahoo.com.br, orcid: http://orcid.org/0000-00025566-3413

${ }^{2}$ Universidade Federal de Jataí, e-mail: fredericoagg@gmail.com, orcid: http://orcid.org/0000-0002-5623-4127

${ }^{3}$ Universidade Estadual de Goiás, e-mail: renato_geografo@hotmail.co, orcid: http://orcid.org/0000-0003-25005468
\end{abstract}

${ }^{4}$ Universidade Federal de Jataí, e-mail: ekailarp@gmail.com, orcid: https://orcid.org/0000-0002-8738-4734

Artigo recebido em 27/07/2020 e aceito em 16/02/2021

\begin{abstract}
RESUMO
A intensificação dos impactos ambientais no Cerrado brasileiro tem proporcionado desrespeitos à legislação e a degradação de ecossistemas nos últimos anos. Áreas úmidas do bioma, como as Veredas, são fisionomias ímpares para manutenção dos recursos hídricos, solos e preservação da biodiversidade. O objetivo desse estudo foi elaborar uma definição para Veredas, adequando à realidade brasileira. Nesse sentido, efetuamos uma análise da legislação ambiental em nível federal e estadual, verificando o grau de proteção jurídica das Veredas, frente às recentes alterações dessas legislações. Para isso, avaliamos documentos de forma indireta sobre a definição, além de revisão e análise da legislação ambiental sobre Veredas. Na esfera federal, a proteção das Veredas foi fragilizada com a criação da Lei $\mathrm{n}^{\circ}$ 12.651. Aliado a isso, poucos estados possuem leis que busquem a proteção dessa fisionomia. Portanto, recomendamos a alteração do conceito legal de Vereda e na sua forma de demarcação.
\end{abstract}

Palavras-chave: Lei ambiental; Degradação; Cerrado; Proteção jurídica.

\section{ANALYSIS OF BRAZILIAN ENVIRONMENTAL LEGISLATION FOR THE PROTECTION OF VEREDAS}

\begin{abstract}
In The intensification of environmental impacts in the Brazilian Cerrado has caused disrespect for legislation and the ecosystems degradation in recent years. Wetlands in Cerrado, such as Veredas, are unique physiognomies for maintaining water resources, soils and preserving biodiversity. This study aimed to develop a definition for Veredas, adapting to the Brazilian reality. In this sense, we carried out an analysis of environmental legislation at the federal and state levels, verifying the degree of legal protection of Veredas, in view of the recent changes in these laws. For this, we evaluate documents indirectly on the definition, in addition to reviewing and analyzing the environmental legislation on Veredas. At the federal level, the protection of Veredas was weakened by the creation of Law No. 12,651. Allied to this, few states have laws that seek to protect this physiognomy. Therefore, we recommend changing the legal concept of Vereda and its form of demarcation.
\end{abstract}

Keywords: Environmental law; Degradation; Brazilian savanna; Legal protection. 


\section{INTRODUÇÃO}

O Cerrado ou savana brasileira é um complexo vegetacional, caracterizado por formações florestais, savânicas e campestres, subdividas em diversas fisionomias (RIBEIRO; WALTER, 2008), resultando em marcante heterogeneidade ambiental. A distribuição do Cerrado está subordinada ao clima Tropical, ao passo que as fisionomias variam em função de fatores abióticos mais específicos, ditados pela geomorfologia, solos e até efeitos de queimadas. Isso resulta em diferenças no adensamento da vegetação (ervas, arbustos ou árvores), as quais se alteram em pequena escala, e também na distribuição das espécies (RIBEIRO; WALTER, 2008).

O Cerrado é reconhecido por ser área de recarga de vários aquíferos, importante na geração das águas continentais. Isso ocorre em diversas fisionomias, tais como: Campo Limpo Úmido, Campo Sujo Úmido, Campo de Murundus, Floresta de Galeria, Várzea e Vereda. As áreas úmidas (AU), como tratadas em várias situações, são áreas de transição na interface entre os ecossistemas terrestres e os ecossistemas aquáticos (NEUE et al., 1997; JUNK et al., 2015). As AU do Cerrado são reguladas pelo regime climático sazonal, sendo importantes fontes de água potável. Sua identificação está em grande parte relacionada ao tipo de vegetação, regime hidrológico e solos hidromórficos (DE-CAMPOS et al., 2013).

Entretanto, as AU são ecossistemas frágeis, de alta complexidade ecológica, fundamentais para a estabilidade ambiental e a manutenção da biodiversidade (HUNG; MARANGON; SANTOS, 2017). Mesmo assim, vem sofrendo degradação severa pela ocupação descontrolada, atividades agropecuárias, expansão urbana e realização de obras de infraestrutura como a construção de rodovias (SANTOS; GUILHERME, 2019). Especificamente, alguns desses impactos ocorrem pela drenagem de áreas para expansão agrícola, contaminação dos solos proveniente do uso de agroquímicos e outros componentes para a correção dos solos (SOUZA; ROSOLEN, 2014).

Dentre as AU do Cerrado, as Veredas são fundamentais à manutenção da vida no bioma, principalmente, pela relação com a disponibilidade de água e para a manutenção da biodiversidade. Veredas ocorrem em solos hidromórficos, com elevada umidade do solo e pouca drenagem. São comuns em terrenos mais aplainados e vales pouco profundos, geralmente de fundo chato, e ainda em áreas de nascentes ou extravasamento do lençol aquífero (FERREIRA, 2008). Outra característica marcante das Veredas é a presença da emblemática palmeira Mauritia flexuosa (família Arecaceae), conhecida vulgarmente como buriti. 
O atual cenário de ocupação do Cerrado, ameaça a conservação das Veredas. Como resultado visível e imediato, a vegetação nativa tem sido substituída principalmente pela agropecuária. Desde a segunda metade do século XX, o Cerrado teve forte alteração de sua paisagem natural (FERNANDES; PESSÔA, 2011). Este processo de alteração da paisagem é agravado ainda pela mineração, silvicultura, expansão dos núcleos urbanos, aumento da malha rodoviária e ferroviária e barramentos de cursos d'água para geração de energia. Consequentemente, a cobertura vegetal original do Cerrado está sendo reduzida gradativamente ao longo dos anos, restando apenas fragmentos disseminados pelas propriedades rurais. As modificações provenientes desta ocupação provocam a perda de espécies nativas e a inserção de espécies exóticas, desencadeando desequilíbrios ambientais. Essa substituição da flora nativa por espécies exóticas tem marcado a destruição das fitofisionomias do Cerrado, além de resultar na dizimação de espécies da fauna (SANTOS et al., 2013).

Nesse cenário, devemos considerar que as Veredas são ecossistemas sensíveis e com baixo potencial de resiliência (BRANDÃO; CARVALHO; BARUQUI, 1991). As zonas de transição entre solos secos e úmidos são locais sensíveis à degradação nessas fisionomias (ROSOLEN et al., 2015). Aos poucos, essas faixas ecotonais vão se perdendo, e as Veredas passam a ter sua área reduzida e/ou alterada a cada novo ciclo de cultivo, pisoteada pelo gado, drenada, queimada ou alagada por represamento.

Existem na literatura várias contribuições importantes sobre as Veredas, como Boaventura (1978; 1988), Castro (1980) e Melo (1992), e mais recentemente, Ramos et al. (2006), Ferreira (2003; 2005/2006; 2008) e Melo (2008). Entretanto, mesmo com o atual quadro de degradação das Veredas, há escassez de estudos sobre limites, fatores de origem e características geomorfológicas. Novos estudos possibilitam uma definição mais precisa desta fitofisionomia, permitindo medidas mais eficazes de proteção e manutenção. Trazer à tona essa análise é fundamental, visto que alterações recentes na legislação ambiental brasileira, com a homologação da Lei $n^{\circ}$ 12.651, de maio de 2012 (BRASIL, 2012a), provocaram dúvidas sobre a proteção das Veredas em toda sua extensão espacial. Para Venancio e Kurtz (2009) a evolução das leis ambientais vem refletindo o contínuo processo de valorização da natureza e dos bens naturais como fator de produção. Assim, diante dessa Lei federal, estados que possuem áreas de Cerrado em seu território passaram a alterar suas leis ambientais, como meras cópias da legislação federal. Desse modo, as legislações ambientais nas esferas federal e estadual apresentam problemas quanto à definição e delimitação de Veredas, comprometendo sua função de proteção legal. 
Nesse contexto, o atual estudo pretende discutir os aspectos legais sobre a definição de limites das Veredas, bem como, efetuar análise da legislação ambiental brasileira em nível federal e estadual, visando analisar o grau de proteção legal dessa fisionomia, frente a recentes alterações dessas legislações. O estudo foi pautado na análise de documentação indireta sobre sua definição, além de revisão e análise da legislação ambiental vigente.

\section{MATERIAL E MÉTODOS}

O presente estudo está baseado em pesquisa bibliográfica e análise do material encontrado sobre a caracterização, definição e atual legislação ambiental brasileira para a proteção das Veredas. Para a análise sobre o termo Vereda foram consultados estudos clássicos que trazem algum tipo de definição conceitual. Posteriormente, buscamos novos estudos sobre o tema, em artigos de periódicos científicos, bancos de teses e dissertações. As diversas definições foram comparadas entre si, sendo separado cada aspecto que as integram. Com a análise de todas as definições encontradas e dos diferentes aspectos empregados na criação destas, foi então possível a proposição de nova definição mais condizente com o atual nível de estudos, e maior capacidade de retratar a diversidade das Veredas. Diante disso, iniciamos buscas na rede mundial de computadores visando encontrar normas jurídicas, (e.g. leis, decretos e resoluções) que fazem menção a proteção de Veredas. A Lei Federal n 12.651 (BRASIL, 2012a) e as normas jurídicas existentes anteriormente a esta lei, foram analisadas visando entender as alterações que ocorreram. Também analisamos o tratamento dado pela norma jurídica brasileira as AU, principalmente, frente a Convenção sobre Zonas Úmidas de Importância Internacional.

Após o estudo da norma jurídica ambiental federal, também realizamos análise, em nível estadual, das legislações ambientais de todas as unidades da federação inseridas integral ou parcial no bioma Cerrado (Goiás, Tocantins e Distrito Federal) (Bahia, Ceará, Maranhão, Mato Grosso, Mato Grosso do Sul, Minas Gerais, Piauí, Rondônia e São Paulo) (RIBEIRO, WALTER, 2008). Além disso, consultamos sites dos órgãos ambientais de cada estado e do Distrito Federal visando encontrar leis ou decretos mencionando Veredas.

De posse dos dados procedemos a análise de toda a legislação encontrada visando entender como está sendo tratada a proteção legal dessa fitofisionomia e como essa legislação tem se alterado ao longo do tempo. Por fim, avaliamos o impacto da Lei $\mathrm{n}^{\circ} 12.651$ (BRASIL, 2012a) na norma jurídica ambiental estadual e na proteção, das Veredas, de um modo geral. 


\section{RESULTADOS E DISCUSSÃO}

\section{Vereda: em busca de uma nova definição}

No mosaico fitofisionômico do Cerrado, as Veredas são peculiares por sua relação com a água e, consequentemente, com os cursos d'água. O termo Vereda está etimologicamente relacionado a caminho estreito, estrada, atalho, azinhaga, picada, senda (AULETE, 1970; BUENO, 1974). Segundo Cunha (1989, p. 312), "Vereda - Caminho estreito, atalho [...] do lat. Veredus - cavalo de posta". No Nordeste do Brasil é usado para região com maior abundância de água, situada em vales; na Bahia como a várzea de um rio; na região central, como matas cercadas por campos, com renques de buritis e pindaíbas (AULETE, 1970). Vereda é um termo regional usado, principalmente, na região das gerais (BOAVENTURA, 1978). As Veredas são predominantes na área nuclear do Cerrado, como o Sudoeste de Goiás, em direção a norte e a leste. Para o sul, à medida que se aproxima do Pantanal Mato-grossense, tendem a desaparecer, ficando apenas os ambientes alagadiços com contornos diferenciados (BARBOSA, 2008).

Ao analisar as definições sobre Veredas, notamos algumas incongruências. Por exemplo, Boaventura (1978) e Melo (2008) consideram apenas um tipo de Vereda, sem levar em conta a grande diversidade dessa fitofisionomia em todo o Cerrado. Diversos outros estudos, tratados a seguir, tentaram defini-la, embora, em uma análise mais detalhada, verificamos que a maioria apenas replica as primeiras definições. Sendo assim, analisamos as principais características das Veredas e que são comumente citadas.

Essa fitofisionomia é constantemente relacionada como área de nascente, extravasamento ou exsudação de lençol de água (BOAVENTURA, 1978; FERREIRA, 2003; MELO, 2008), e todos são unânimes em afirmar que Veredas são áreas de afloramento de lençol de água. Outra característica habitualmente descrita é a presença de solos hidromórficos (CARVALHO, 1991; MELO, 1992; RIBEIRO, WALTER, 2008; FERREIRA, 2003; RAMOS et al., 2006; QUEIROZ, 2015), os quais apresentam drenagem deficiente e saturação por água na maior parte do tempo (NASCIMENTO et al., 2013). Solos hidromórficos são resultantes da atuação de fatores locais, como topografia e lençol freático elevado, formando-se em condições de baixo potencial de oxirredução (BRANDÃO; CARVALHO; BARUQUI, 1991). Predominam nesses solos os processos de gleização e paludização, esse último responsável pelo surgimento das turfeiras (ANJOS et al., 2008). Compreendem solos que estão inseridos em diferentes classes do Sistema Brasileiro de Classificação de Solos, como os Espodosslos, 
Gleissolos, Organossolos e Planossolos (SILVA NETO, 2010). Ainda relacionado à água, vários autores caracterizam a Vereda como local de trama fina e mal delimitada de caminhos de água, área de má drenagem ou área pantanosa ou sistema de drenagem mal delimitado (BOAVENTURA, 1978; FERREIRA, 2003; 2007). Desse modo, má drenagem, condicionada a solos hidromórficos é uma de suas características próprias e fator limitante para ocorrência de Veredas.

A ocorrência de buritis, em geral, é uma característica marcante dessa fisionomia. Para Carvalho (1991), ao menos nos primeiros estágios evolutivos da Vereda, o buriti está presente e é tratado como espécie símbolo das Veredas, pela sua pujança e aspecto estético-paisagístico (FERREIRA, 2003; 2009). Segundo Queiroz (2015), AU associadas a cursos d'água semelhantes às Veredas, sem ocorrência de buritis, mas ocupadas por outros agrupamentos de palmeiras, como açaizais e carnaubais, tipificam fisionomias distintas de Veredas.

Ribeiro e Walter (2008), embora afirmem que Veredas são áreas de ocorrência do buriti, diferenciam duas fitofisionomias, nas quais pode ocorrer o buriti. Para eles, tanto Buritizal quanto Vereda englobam as formações savânicas, ou seja, ambientes tipicamente abertos, não florestais. Entretanto, as Veredas proporcionam cobertura de dossel entre 5\% e 10\%, diferente dos Buritizais, com cobertura mais densa. Por outro lado, Florestas de Galeria, uma fisionomia florestal típica do Cerrado, também podem apresentar buritis. Desse modo, os locais com ocorrência de buritis, em que haja marcada ocorrência de outras espécies vegetais lenhosas e sem formas campestres associadas, não podem ser consideradas como Veredas ou Buritizais.

Cunha, Piedade e Junk (2015) propuseram uma chave de classificação de AU no Brasil. Inseriram na categoria Buritizal, formações presentes tanto no Cerrado como no bioma Amazônico. Entretanto, pela falta de estudos relatada pelos próprios autores, é difícil a junção de áreas presentes nesses dois biomas. Nesse sentido, tratamos aqui especificamente do Cerrado. Essa discussão demonstra o quão complexos são esses ecossistemas. Para tentar abarcar essa complexidade, devemos, inicialmente, reconhecer que não existe um modelo único de Vereda, assim como fizeram alguns autores ao diferenciá-la quanto às características geomorfológicas, tipo de aquífero do qual se originam, estágios evolutivos e características fisionômicas (BOAVENTURA, 1978; 1988; CARVALHO, 1981; BRANDÃO, CARVALHO, BARUQUI, 1991; FERREIRA, 2005/2006). Na dependência das características geomorfológicas regionais das Veredas, estas passarão por estágios evolutivos, cada um com um conjunto de espécies e adensamento próprios. Nesse sentido, as diversas fisionomias existentes para a Vereda representam o estágio sucessional, frente às características geomorfológicas. 
Nesse sentido, adotamos o entendimento de que a presença do buriti é característica definidora da Vereda, fazendo parte da sua composição paisagística (FERREIRA, 2009). Diante desse entendimento e da proposição dos estágios evolutivos de Vereda, torna-se difícil definir e segregar os Buritizais das Veredas, como proposto por Ribeiro e Walter (2008), pois as duas fitofisionomias compartilham as mesmas características geomorfológicas, hidrológicas e pedológicas, bem como, cumprem a mesma função ecológica e são reconhecidas pelas populações locais, como sendo uma única paisagem, Vereda, embora, conforme Ribeiro e Walter (2008), apresentem consideráveis diferenças florísticas.

Sobre a formação de dossel, Queiroz (2015) afirma que a concentração de palmeiras é variável e não forma apenas renques ou alamedas, mas também dossel, ao longo de uma mesma Vereda. Dessa forma, a diferenciação quanto à formação de dossel, presença ou não de formação campestre, ou mesmo florística, é perfeitamente justificável pelos diversos estágios evolutivos da Vereda. Além disso, é preciso considerar que a Vereda é dinâmica e transicional com Florestas de Galeria e Ciliar, Campo Úmido e outras (QUEIROZ, 2015). Por esse motivo, é considerada como complexo vegetacional (BRANDÃO, CARVALHO, BARUQUI, 1991; ARAÚJO et al., 2002; CUNHA, PIEDADE, JUNK, 2015).

A diferenciação de áreas em que ocorre o buriti em conjunto com diversas outras espécies arbóreas, fisionomicamente próxima a Floresta de Galeria, também é difícil. Boaventura (1988) reconheceu que em Vereda pode ocorrer formação florestal junto a buritis, e ao propor unidades de mapeamento no Noroeste Mineiro, cita a Vereda como comunidade especial hidrófila incluindo, em alguns locais, manchas pequenas de floresta perenifólia (Mata de Alagados), de composição florística muito específica. Embora floristicamente diferente do que se chama de Vereda típica, não pode ser desmembrada da noção de Vereda, pois a simples presença do buriti indica a presença de água constante no perfil, solos hidromórficos e ambiente mal drenado, já que essa espécie não ocorre em locais sem essas características. Embora a presença de espécies arbóreas indique a melhora na drenagem do solo, ainda assim é possível a ocorrência de Vereda, mesmo que em seu último estágio evolutivo, conforme explica Carvalho (1991).

A Vereda, compreendida como um oásis por aqueles que habitam o Cerrado, é local onde facilmente se encontra água, muitas vezes na imensidão de áreas circundantes secas. Além das características já elencadas como forma de diferenciar a Vereda, devemos acrescentar que a Vereda participa do controle do fluxo do lençol freático, desempenhando um papel fundamental no equilíbrio hidrológico dos cursos d'água, constituindo um sistema armazenador 
de água importante para a perenidade e regularidade dos cursos d'água do Cerrado (CARVALHO, 1991; FERREIRA, 2003; RAMOS et al., 2006).

Diante de toda essa discussão, assumimos um conceito fundamentado no atual conhecimento sobre essa fitofisionomia. Veredas são AU presente no bioma Cerrado, sobre solos hidromórficos, com formas diversas de relevo, geralmente, fundo plano a suave ondulado e vertentes suaves. Apresentam cobertura vegetal caracterizada por plantas hidrófila em campo graminoso-herbáceo e/ou estrato arbustivo-herbáceo, sempre associados aos buritis.

\section{Áreas úmidas e Veredas no contexto da legislação ambiental brasileira}

As AU tiveram maior notoriedade em todo Planeta a partir da Convenção sobre Zonas Úmidas de Importância Internacional, conhecida como Convenção de Ramsar, (Irã, fevereiro de 1971), embora tenha entrado em vigor em 1975. A Convenção é um tratado intergovernamental criado, inicialmente, no intuito de proteger habitats aquáticos importantes para a conservação de aves migratórias. Mas, ao longo do tempo, ampliou sua preocupação com as demais AU (BRASIL, 2018). Seus signatários têm como obrigações, entre outras, a criação de Lista de Zonas Úmidas de Importância Internacional e a promoção da conservação de zonas úmidas e de aves aquáticas, independentemente de estarem listadas. O Brasil é signatário dessa Convenção desde 1993, tendo incorporado seus aspectos ao arcabouço legal, através do Decreto $\mathrm{n}^{\circ}$ 1.905, de 16 de maio de 1996 (BRASIL, 1996). Atualmente, no Brasil, existem 27 Zonas Úmidas listadas, chamados de Sítios Ramsar. Embora as Veredas não estejam incluídas nesta lista, o artigo $4^{\circ}$ do Decreto $n^{\circ} 1.905$ determina que "Cada parte contratante deverá promover a conservação de zonas úmidas e de aves aquáticas estabelecendo reservas naturais nas zonas úmidas, quer estas estejam ou não inscritas na Lista, e providenciar a sua proteção apropriada" (BRASIL, 1996). Desse modo, mesmo que não integrem na Lista, as Veredas, reconhecidas como AU de elevada importância ecológica, tem sua proteção garantida.

Ainda sobre a proteção das AU na norma jurídica brasileira devemos ressaltar que a Constituição da República Federativa do Brasil, de 5 de outubro de 1988 (BRASIL, 1988) estabelece em seu artigo 225, parágrafo $1^{\circ}$, inciso III, a obrigatoriedade do Poder Público em: "definir, em todas as Unidades da Federação, espaços territoriais e seus componentes a serem especialmente protegidos, sendo a alteração e a supressão permitidas somente através de lei, vedada qualquer utilização que comprometa a integridade dos atributos que justifiquem sua 
proteção". Tendo sido regulamentado pela Lei n 9.985, de 18 de julho de 2000 (BRASIL, 2000) no âmbito do Sistema Nacional de Unidade de Conservação da Natureza (SNUC).

Para Antunes (2019) os Espaços Territoriais Especialmente Protegidos (ETEP) no Direito brasileiro podem ser divididos em dois grupos, os criados por força de Lei e os criados por ato do Poder Público. Os primeiros são aplicáveis em todo o território nacional, bastando que as características previstas legalmente se encontrem presentes sobre o território para que incida a proteção legal. Os segundos são os que demandam ato concreto para a sua instituição, confundindo-se com as chamadas Unidades de Conservação (UC) (ANTUNES, 2019).

Entre os ETEP criados por força de Lei estão aqueles tratados pela Lei $\mathrm{n}^{\circ} 12.651$ (BRASIL, 2012) (e.g. Áreas de Preservação Permanente-APP, Reserva Legal e Área de Uso Restrito). Essa Lei também faz referência as AU, em seu artigo 3º inciso XXV, define “Áreas úmidas: pantanais e superfícies terrestres cobertas de forma periódica por águas, cobertas originalmente por florestas ou outras formas de vegetação adaptadas à inundação". Entretanto, essa definição é diferente daquela presente na Convenção de Ramsar, bem como, pouco específica e de difícil aplicação prática. Ainda com base na Lei no 12.651, observamos que as AU, como, Veredas, manguezais, salgado ou marismas tropicais hipersalinos, apicuns, restingas, várzeas e olhos d'água estão tratadas de forma separada, com critérios próprios de identificação. Com a análise da legislação ambiental brasileira, notamos a adoção de conceitos diversos e sem uma padronização, o que dificulta a proteção de toda essa diversidade ecossistêmica. $\mathrm{O}$ artigo $6^{\circ}$ da referida Lei traz a possibilidade de inserção, como APP, de áreas declaradas de interesse social e, em seu inciso IX, cita "proteger AU". Assim, existe a possibilidade da inserção da proteção de outras AU que não estão individualizadas na Lei. Em análise sobre o tratamento dessa Lei, Queiroz (2015) argumenta que a principal fragilidade conceitual de AU é a imprecisão quanto à grande abrangência do termo. Afirma ainda que o inventário de AU ainda não foi implementado no País, limitando e inviabilizando a criação de APP. As AU não são consideradas como ecossistemas específicos na legislação ambiental brasileira, e, apesar das suas condições peculiares, são tratadas como ecossistemas terrestres (PIEDADE; JUNK; CANDOTTI, 2014). Desse modo, notamos a necessidade de melhoria no âmbito legal, quanto à definição e proteção das AU.

O Brasil não há um regime jurídico específico para a proteção dos Sítios Ramsar, pois estes foram criados de modo a corresponder em localização e área com UC preexistentes, sendo que a efetiva proteção dada a essas áreas está prevista na Lei do SNUC, e não da Convenção de 
Ramsar. O nível da qualidade de proteção varia de acordo com o tipo de UC correspondente a cada Sítio. Ainda que se possa afirmar que esses Sítios são protegidos no Brasil, falta uma norma específica, que vincule as atividades empreendidas nos sítios às finalidades perpetuadas pela Convenção Ramsar (GRANZIERA; ADAME; GALLO, 2006).

Atualmente, ao buscarmos a base da proteção legal de Veredas, no âmbito nacional, devemos recorrer à Lei Federal $n^{\circ} 12.651$ (BRASIL, 2012a). Todavia, não se pode desconsiderar as leis e resoluções anteriores sobre o tema (Resolução CONAMA - 004/85 e 303/02). Antes da análise da atual situação de proteção legal dessa fitofisionomia, observaremos como era tratada pelas legislações anteriores, no intuito de analisar se essa proteção tem sido efetivamente mantida ou melhorada. Veredas foram citadas em legislação federal pela primeira vez na Resolução ${ }^{\circ}$ 004, do Conselho Nacional do Meio Ambiente (CONAMA), de 18 de setembro de 1985, referente às Reservas Ecológicas:

Art. $2^{\circ}$ - Para efeitos desta Resolução são estabelecidas as seguintes definições: [...] e) - Vereda- nome dado no Brasil Central para caracterizar todo espaço brejoso ou encharcado que contêm nascentes ou cabeceiras de cursos d'água de rede de drenagem, onde há ocorrência de solos hidromórficos com renques de buritis e outras formas de vegetação típica; [...]

Art. $3^{\circ}$ - São Reservas Ecológicas: [...]

III - nas nascentes permanentes ou temporárias, incluindo os olhos d'água e Veredas, seja qual for sua situação topográfica, com uma faixa mínima de 50 (cinqüenta) metros e a partir de sua margem, de tal forma que proteja, em cada caso, a bacia de drenagem contribuinte (BRASIL, 1985).

Entretanto, ainda não há uma clara definição a seu respeito como APP (MARTINS et al., 2017). Após essa primeira citação em instrumento legal, as Veredas apareceram novamente na Resolução CONAMA n ${ }^{\circ}$ 303, de 20 de março de 2002, que dispõe sobre parâmetros, definições e limites de APP:
Art. $2^{\circ}$ Para os efeitos desta Resolução, são adotadas as seguintes definiç̧̃es: [...]
II - Vereda: espaço brejoso ou encharcado, que contém nascentes ou cabeceiras de cursos d’água, onde há ocorrência de solos hidromórficos, caracterizado predominantemente por renques de buritis do brejo (Mauritia flexuosa) e outras formas de vegetação típica; [...] Art. $3^{\circ}$ Constitui Área de Preservação Permanente a área situada: [...]
IV - em Vereda e em faixa marginal, em projeção horizontal, com largura mínima de cinqüenta metros, a partir do limite do espaço brejoso e encharcado (BRASIL, 2002).

Ao analisar a Resolução CONAMA nº 303 (BRASIL, 2002), notamos que ocorreram avanços em relação à Resolução CONAMA nº 004 (BRASIL, 1985), especialmente quanto a definição mais objetiva e de mais fácil aplicação. Embora tenham sido mantidos alguns pontos controversos, a própria definição de Veredas, ainda continha problemas, pois não era capaz de 
abarcar todas as peculiaridades dessas fisionomias. Outro problema era a dificuldade da definição do limite do espaço brejoso e encharcado. Veredas também foram citadas na Resolução CONAMA n 369, de 28 de março de 2006 (BRASIL, 2006), que dispunha sobre os casos excepcionais que possibilitavam a intervenção ou supressão de vegetação em APP.

Posteriormente, criou-se a Lei no 12.651 (BRASIL, 2012a), a qual passou por várias modificações. Dentre estas alterações, a Lei nº 12.727, de outubro de 2012 (BRASIL, 2012a), foi responsável por modificar o conceito de Vereda, que passou a vigorar como:

XII - Vereda: fitofisionomia de savana, encontrada em solos hidromórficos, usualmente com a palmeira arbórea Mauritia flexuosa - buriti emergente, sem formar dossel, em meio a agrupamentos de espécies arbustivo-herbáceas (BRASIL, 2012b).

Com essa definição, em função do termo "usualmente", a presença do buriti não é obrigatória para a caracterização de uma Vereda, contrariando vários estudos (e.g. FERREIRA, 2003; 2009; QUEIROZ, 2015). Ainda em relação à vegetação, verificamos a necessidade de ocorrência de "agrupamentos de espécies arbustivo-herbáceas", entretanto em alguns tipos de Veredas esse estrato vegetativo pode não ocorrer. Outro problema dessa conceituação é a obrigatoriedade de que o buriti ocorra "sem formar dossel", pois conforme demonstrado, a Vereda pode ocorrer mesmo em locais em que o buriti forma dossel contínuo. Assim, verificamos que a legislação falha ao conceituar o termo Vereda e em não considerar o debate teórico existente. Ao invés de caracterizar o espaço protegido, a nova lei descreve a fitofisionomia (MINISTÉRIO PÚBLICO DE GOIÁS, 2015).

Outro problema da Lei n ${ }^{\circ} 12.651$ para a proteção das Veredas, ocorre quanto à faixa considerada APP, no seu entorno. Na Resolução CONAMA n 303 constava "em Vereda e em faixa marginal", ao passo que a referida Lei passou a figurar "em Veredas, a faixa marginal". Essa alteração pode causar interpretações dúbias, visto que Veredas, não são mais consideradas como APP, mas apenas a sua faixa marginal. Nesse contexto, subentende que Veredas propriamente ditas não constituem APP, mas apenas a faixa marginal (MARTINS et al., 2017). Ainda segundo a Lei $\mathrm{n}^{\circ}$ 12. 651, APP em Veredas são determinadas a partir do "espaço permanentemente brejoso e encharcado". Desconsidera ainda que Veredas ocorrem em clima Tropical, com período seco pronunciado e possui uma zona de umidade sazonal (sensu MELO, 2008), também chamada de zona da borda (ARAÚJO et al., 2002). Desse modo, essa zona de umidade sazonal passa a não ser considerada como parte integrante das Veredas (MARTINS et al., 2017). Essa Lei também flexibiliza a preservação das Veredas ao admitir atividades 
humanas na APP (ROSOLEN et al., 2015), além da permissibilidade da continuidade de atividades agrossilvipastoris, de ecoturismo e de turismo rural, em APP, desde que consolidadas até julho de 2008. Todavia, podemos considerar benéfico seu artigo $6^{\circ}$ ao possibilitar a criação de APP, se declaradas de interesse social por ato do Chefe do Poder Executivo, quando forem para proteger as restingas ou Veredas.

Diante de toda essa análise da Lei $\mathrm{n}^{\circ}$ 12. 651 (BRASIL, 2012a), historicamente, observamos que houve retrocesso na proteção das Veredas. Portanto, é crucial a revisão de sua definição, visando abarcar os diferentes tipos de Veredas existentes. Também é necessária a correção do artigo $4^{\circ}$, alínea XII, para que não existam dúvidas da proteção direta de toda extensão dessas AU e não apenas a sua faixa marginal. Outra alteração recomendada é na forma como se define o limite de uma Vereda, o ideal seria através da presença de solos hidromórficos e não a partir de solo permanentemente brejoso e encharcado, como demonstra Barbosa (2016).

\section{Especificidades das legislações estaduais}

No estado de Goiás, o Código Florestal, Lei no 12.596, de 14 de maço de 1995 (GOIÁS, 1995), além de reconhecer o Cerrado como Patrimônio Natural do estado, incluí as Veredas como APP. Entretanto, estipula que apenas Veredas são APP e não determina a proteção em faixa marginal. Essa foi revogada pela Lei no 18.104, de 18 de junho de 2013 (GOIÁS, 2013), que dispõe sobre a proteção da vegetação nativa, e institui a nova política florestal do estado de Goiás.

A Lei no 18.104 conceitua em seu artigo 5, inciso XI, "Vereda: fitofisionomia de Savana, encontrada em solos hidromórficos, usualmente com a presença da palmeira Mauritia flexuosa (buriti) emergente, sem formar dossel, em meio a agrupamentos de espécies arbustivo-herbáceas" (GOIÁS, 2013). Esse conceito é cópia fiel da Lei Federal n 12. 651 e apresenta um retrocesso em relação à legislação anterior, pois não se prevê APP especificamente em Vereda. Outra referência à Vereda ocorre no artigo $17^{\circ}$, da referida Lei, "Nos casos de áreas rurais consolidadas em Veredas, será obrigatória a recomposição das faixas marginais, em projeção horizontal, delimitadas a partir do espaço brejoso e encharcado [...]" (GOIÁS, 2013). Mais uma vez, redação muito próxima ao que consta na Lei Federal e, assim, compartilha dos mesmos problemas.

O estado de Tocantins possui em toda sua legislação ambiental uma única referência à Vereda. A Lei n ${ }^{\circ} 1.939$, de 24 de junho de 2008 (TOCANTINS, 2008), que dispõe sobre os casos excepcionais que possibilitam a intervenção ou supressão de vegetação em APP, em seu artigo $2^{\circ}$, parágrafo $1^{\circ}$, “É vedada a intervenção ou supressão de vegetação em APP de nascentes, 
Veredas e dunas originalmente providas de vegetação, salvo nos casos de utilidade pública e para o acesso de pessoas e animais para obtenção de água” (TOCANTINS, 2008). Tocantins tem a quase totalidade de seu território na área nuclear do Cerrado, mas sua legislação não trata de forma específica da proteção das Veredas.

Em toda a legislação ambiental do Distrito Federal existe apenas uma referência específica sobre Vereda e outra sobre o buriti. A Lei Complementar n² 265, de dezembro de 1999 (DISTRITO FEDERAL, 1999), que dispõe sobre a criação de Parques Ecológicos e de Uso Múltiplo no Distrito Federal, estabelece em seu artigo $4^{\circ}$, que os Parques Ecológicos devem possuir APP, nascentes, olhos d'água, Veredas, Matas Ciliares, Campos de Murundus ou manchas representativas de qualquer fitofisionomia do Cerrado que abranjam, no mínimo, 30\% da área total da unidade (DISTRITO FEDERAL, 1999). O Decreto $\mathrm{n}^{\circ}$ 14.783, de 17 de junho de 1993 (DISTRITO FEDERAL, 1993), que dispõe sobre o tombamento de espécies arbóreo-arbustivas, estabelece que estão tombadas como Patrimônio Ecológico do Distrito Federal, dentre outras espécies, o buriti (Mauritia flexuosa L.f.). Esse decreto foi alterado recentemente pelo Decreto ${ }^{\circ} 38.849$, de 08 de fevereiro de 2018 (DISTRITO FEDERAL, 2018), mas a redação sobre a proteção do buriti não foi alterada. Outras leis estaduais, como a Política Florestal, não fazem nenhuma menção às Veredas.

O estado da Bahia, através da sua Constituição de 05 de outubro de 1989, artigo 216², inciso VI, afirma que "os vales e as Veredas dos afluentes da margem esquerda do rio São Francisco", constituem patrimônio estadual e sua utilização far-se-á na forma da lei (BAHIA, 1989). O estado tem ainda outras leis que discorrem sobre as Veredas. A Lei nº 6.569, de 17 de janeiro de 1994, que dispõe sobre a Política Florestal no estado da Bahia, no artigo 23º parágrafo $2^{\circ}$, afirma que a exploração dos recursos naturais nas Veredas dependerá de licenciamento do órgão competente (BAHIA, 1994). A Lei $n^{\circ} 6.569$ foi revogada pela Lei $n^{\circ} 10.431$, de 20 de dezembro de 2006 (BAHIA, 2006), que dispõe sobre a Política de Meio Ambiente e de Proteção à Biodiversidade do estado da Bahia. Essa nova Lei, em seu artigo $90^{\circ}$, afirma que são também consideradas APA, as áreas cobertas ou não por vegetação natural situadas nas Veredas do Oeste do estado e brejos litorâneos. Na mesma Lei, o artigo $96^{\circ}$, inciso VI, reafirma que os vales e as Veredas dos afluentes da margem esquerda do rio São Francisco, constituem patrimônio estadual, nos termos da Constituição estadual (BAHIA, 2006). A Lei no 12.377, de 28 de dezembro de 2011 (BAHIA, 2011), alterou a Lei n ${ }^{\circ} 10.431$, assim o artigo 90 , passou a vigorar com a seguinte redação, "São também consideradas de preservação permanente as áreas cobertas ou não por 
vegetação natural situadas nas Veredas do Oeste do Estado e brejos litorâneos, cujos limites serão definidos em regulamento, de modo a garantir e proteger os mananciais" (BAHIA, 2011).

O estado do Ceará, através do Decreto no 24.221, de 12 de setembro de 1996 (CEARÁ, 1996), que regulamenta a Lei no 12.488 de 13 de setembro de 1995 (CEARÁ, 1995), dispõe sobre a Política Florestal do estado, faz menção a proteção das Veredas. No referido decreto, Veredas são consideradas um tipo de Reserva Ecológica, que integra as UC. O Decreto $\mathrm{n}^{\circ} 24.221$ determina:

\footnotetext{
Art. $7^{\circ}$. São Unidades e Conservação de uso indireto, de domínio público e que não permitem a exploração dos recursos naturais: [...]

IV - Reservas Ecológicas; [...]

IV - Reservas Ecológicas, assim definidas: [...]

b) as florestas e demais formas de vegetação natural situadas: [...]

3. nas nascentes permanentes ou temporárias, incluindo os olhos d'água e Veredas, seja qual for sua situação topográfica com uma faixa mínima de 50 (cinquenta) metros a partir de sua margem, de tal forma que proteja, em cada caso, a bacia de drenagem contribuinte (CEARÁ, 1996).
}

No estado do Maranhão existe a Lei estadual $n^{\circ}$ 5.405, de 05 de abril de 1992 (MARANHÃO, 1992), que Institui o Código de Proteção de Meio Ambiente e dispõe sobre o Sistema Estadual de Meio Ambiente e o uso adequado dos recursos naturais. No artigo $16^{\circ}$, inciso XI, afirma que compete a Secretaria de Estado de Meio Ambiente e Recursos Hídricos, preservar de modo permanente os buritizeiros (MARANHÃO, 1992). Essa é a única referência que pode ser correlacionada com as Veredas, mas por ser demasiadamente vaga, não se pode instaurar qualquer proteção efetiva. O mesmo ocorre no estado do Piauí, no qual a Lei nº 3.888, de 26 de setembro de 1983 (PIAUÍ, 1983), em seu artigo $1^{\circ}$, proíbe o corte de algumas palmáceas, dentre elas, o buriti, o que não representa proteção efetiva para a Vereda.

No estado de Mato Grosso, a Lei Complementar n ${ }^{\circ} 38$, de 21 de novembro de 1995, dispõe sobre o Código Estadual do Meio Ambiente, em seu artigo 58 , alínea c, define a Vereda como APP, "nas nascentes, ainda que intermitentes, nos chamados "olhos d'água", qualquer que seja sua situação topográfica, nas Veredas e nas cachoeiras ou quedas d'água, num raio mínimo de 100m (cem metros)" (MATO GROSSO, 1995). Importante observar a exigência de um raio mínimo de 100 metros, embora não estipule a partir de qual local deve-se iniciar essa medida, o que dificulta a aplicabilidade da Lei. Entretanto, a Lei foi constantemente alterada por outras posteriores, até que com a aprovação da Lei Complementar n 412, de 13 de dezembro de 2010, passa a figurar a seguinte alteração artigo $58^{\circ}$, alínea c, "nas nascentes, ainda que intermitentes e nos chamados "olhos d'água", qualquer que seja a sua situação topográfica, num raio mínimo de 50 (cinquenta) metros de largura" (MATO GROSSO, 2010). Desse modo, foi retirada a menção 
a Vereda e foi reduzida a área de proteção. A última alteração na Lei Complementar $n^{\circ} 38$, foi efetuada com a Lei Complementar $\mathrm{n}^{\circ}$ 595, de 10 de agosto de 2017 (MATO GROSSO, 2017), sem qualquer alteração quanto a APP e, portanto, não existe mais a menção à Vereda.

O estado de Minas Gerais lança a Lei no 9.375, de 12 de dezembro de 1986 (MINAS GERAIS, 1986), que declara de interesse comum e de preservação permanente os ecossistemas das Veredas do Vale do Rio São Francisco. Essa Lei foi parcialmente alterada pela Lei $n^{\circ}$ 9.682, de 12 de outubro de 1988 (MINAS GERAIS, 1988), que passa a declarar de interesse comum e de preservação permanente os ecossistemas das Veredas do estado. Na prática houve a extensão da legislação para abarcar todo ecossistema de Vereda em Minas Gerais. A Lei assim determina:

Art. $1^{\circ}$ - São declarados de preservação permanente e de interesse comum, nos termos dos artigos $1^{\circ}, 2^{\circ}$ e $3^{\circ}$, alíneas e, f e h da Lei Federal no 4.771, de 15 de setembro de 1965, os ecossistemas das Veredas no Estado de Minas Gerais.

$\S 1^{\circ}$ - O disposto nesta Lei aplica-se às formações fitoecológicas conhecidas como Veredas, caracterizadas pela presença dos buritis (Mauritia sp.) ou outras formas de vegetação típica, em áreas de exsudação do lençol freático que contenham nascentes ou cabeceiras de cursos d'água de rede de drenagem, onde há ocorrência de solos hidromórficos.

$\S 2^{\circ}$ - São consideradas como reservas ecológicas as áreas de Veredas, estabelecidos os seguintes limites:

I - nas Veredas de encosta - toda a sua extensão e até 50 (cinqüenta) metros além da ocorrência de espécies herbáceas, buritis ou solos hidromórficos;

II - nas Veredas de superfície aplainada - toda a sua extensão e até 80 (oitenta) metros além do limite da ocorrência de espécies herbáceas, buritis ou solos hidromórficos;

III - nas Veredas-várzea - toda a sua extensão e até 80 (oitenta) metros além do limite da ocorrência de espécies herbáceas, buritis ou solos hidromórficos (MINAS GERAIS, 1986)

Interessante observar que, embora a conceituação do termo Vereda seja demasiadamente genérica, ocorre a distinção de três diferentes tipos de Veredas, assim como a classificação de Boaventura (1988). Essa é a única legislação no País com tal distinção. Na Lei também estão presentes os conceitos desses tipos de Veredas em seu artigo $1^{\circ}$, parágrafo $3^{\circ}$ :

$\S 3^{\circ}$ - Para efeito de aplicação do disposto no parágrafo anterior, as Veredas serão classificadas, considerando-se as seguintes características:

I - Veredas de encosta - as situadas em áreas de exsudação do lençol freático, com solo arenoso, e eventualmente argiloso solo hidromórfico - com cobertura vegetal herbácea, com a presença ou não de buritis, ocorrendo nas bordas de chapadas, em declives pouco acentuados, em formas semelhantes a meia-lua;

II - Veredas de superfície aplainada - as situadas em áreas de exsudação do lençol freático, com solo argiloso, freqüentemente turfoso na zona encharcada, e solo arenoso ou siltoso na zona menos úmida - solo hidromórfico -, com a presença ou não de buritis e matagaleria;

III - Veredas-várzea - as situadas em áreas de exsudação do lenço freático, em transição para áreas de acumulação de sedimentos aluviais, típicos de planície de inundação ou várzea, com vegetação transicional de espécies herbáceas e buritizais para mata-galeria (MINAS GERAIS, 1986) 
A Constituição de Minas Gerais, de 1989 (MINAS GERAIS, 1989), em seu artigo 214º, parágrafo 7, determina que, as Veredas, “[...] constituem patrimônio ambiental do Estado e sua utilização se fará, na forma da lei, em condições que assegurem sua conservação". Todavia, no ano de 2002, o Governo de Minas Gerais, sancionou a Lei Florestal Estadual nº 14.309, de 19 de junho de 2002 (MINAS GERAIS, 2002), que dispõe sobre as Políticas Florestais e de Proteção à Biodiversidade no Estado. Nessa Lei ocorre referência à Vereda como APP, mas não se estabelece nenhuma faixa marginal e não se utilizam os parâmetros topográficos para a identificação dos diferentes tipos de Veredas. Portanto, um retrocesso em relação à Lei Estadual nº 9.682.

No ano de 2013, o Governo de Minas Gerais, revoga a Lei 14.309, com a publicação da Lei $\mathrm{n}^{\circ}$ 20.922, de 16 de outubro de 2013 (MINAS GERAIS, 2013), que dispõe sobre as Políticas Florestais e de Proteção à Biodiversidade no Estado. No artigo $2^{\circ}$, inciso XV, dessa Lei, a Vereda é conceituada como "[...] fitofisionomia de savana, encontrada em solos hidromórficos onde o lençol freático aflora na superfície, usualmente com a palmeira arbórea Mauritia flexuosa - buriti, emergente em meio a agrupamentos de espécies arbustivo-herbáceas" (MINAS GERAIS, 2013). Conceito muito próximo ao apresentado pela Lei Federal no 12. 651 (BRASIL, 2012a). Na Lei $n^{\circ}$ 20.922, o Governo de Minas Gerais, ao estabelecer a APP em Vereda, também segue a mesma redação da Lei Federal, colocando como APP, apenas a faixa marginal e não a Vereda propriamente dita, como pode ser verificado no artigo $9^{\circ}$, inciso IX, “em Veredas, a faixa marginal, em projeção horizontal, com largura mínima de $50 \mathrm{~m}$ (cinquenta metros), a partir do término da área de solo hidromórfico" (MINAS GERAIS, 2013). O único ponto positivo da redação desse inciso é que o limite da Vereda deve ser considerado a partir do solo hidromórfico e não do espaço permanentemente brejoso e encharcado, como na Lei Federal. Destaca-se que em seu artigo $16^{\circ}$, parágrafo $6^{\circ}$, é reconhecida a função de corredor ecológico e refúgio úmido exercida pela Vereda:

\footnotetext{
$\S 6^{\circ}$ No caso de Vereda ocupada por agricultor familiar, nos termos do art. $3^{\circ}$ da Lei Federal $\mathrm{n}^{\circ} 11.326$, de 2006, fica garantida a continuidade das atividades econômicas relacionadas com as cadeias da sociobiodiversidade na área de recomposição a que se refere o inciso I do $\S 5^{\circ}$ deste artigo, observadas as seguintes condições:

I - manutenção da função de corredor ecológico e refúgio úmido exercida pela Vereda no bioma Cerrado e nos ecossistemas associados (MINAS GERAIS, 2013).
}

Outros pontos da Lei estadual (Lei $\mathrm{n}^{\circ}$ 20.922), como, a possibilidade de declaração de APP em Vereda pelo Chefe do Poder Executivo, a obrigação de recomposição da Vereda em área rural consolidada, seguem o mesmo modelo da Lei Federal. 
No estado de Rondônia a única referência às Veredas, encontra-se na Lei ${ }^{\circ} 1.861$, de 10 de janeiro de 2008 (RONDÔNIA, 2008), que define e disciplina a Piscicultura no estado. No artigo $5^{\circ}$, parágrafo $5^{\circ}$, afirma "É vedada a intervenção ou supressão de vegetação em APP de nascentes, Veredas, manguezais e dunas originalmente providas de vegetação, prevista nos incisos II, IV, X e XI do artigo $3^{\circ}$ da Resolução CONAMA n ${ }^{\circ}$ 303, de 20 de março de 2002.”. Portanto, observamos que o artigo $5^{\circ}$ versa sobre o aproveitamento da APP antropizada para a atividade de piscicultura.

$\mathrm{Na}$ legislação do estado de São Paulo, a única referência às Veredas ocorre na Lei $\mathrm{n}^{\circ}$ 15.684, de 14 de janeiro de 2015 (SÃO PAULO, 2015), que dispõe sobre o Programa de Regularização Ambiental -(PRA), sobre a aplicação da Lei Complementar Federal no 140, de 8 de dezembro de 2011, no âmbito do estado. Na referida Lei, a citação à Vereda ocorre no artigo $14^{\circ}$ :

\footnotetext{
Artigo 14 - A recomposição das Áreas de Preservação Permanente poderá ser feita, isolada ou conjuntamente, nos prazos do PRA, pelos seguintes métodos: [...]

$\S 8^{\circ}$ - Nos casos de áreas rurais consolidadas em Veredas, será obrigatória a recomposição das faixas marginais, em projeção horizontal, delimitadas a partir do espaço permanentemente brejoso e encharcado, de largura mínima de:

1 - 30 (trinta) metros, para os imóveis rurais com área de até 4 (quatro) módulos fiscais;

2 - 50 (cinquenta) metros, para os imóveis rurais com área superior a 4 (quatro) módulos fiscais. [...]

Artigo 22 - A medição da metragem de APP relacionada com os recursos hídricos partirá: [...]

IV - na ocorrência de Vereda no cerrado paulista, o início da medição será em faixa marginal, em projeção horizontal, com largura de 50 (cinquenta) metros, a partir do espaço permanentemente brejoso e encharcado, como previsto na Lei Federal nº 12.651 , de 25 de maio de 2012. (SÃO PAULO, 2015).
}

Portanto, além de não ser uma legislação na qual se busca diretamente a proteção da Vereda, observamos que segue os mesmos parâmetros da Lei Federal n 12. 651 (BRASIL, 2012a).

Por fim, não foi encontrada qualquer referência às Veredas e/ou aos buritis ou buritizais, nas leis ambientais do estado de Mato Grosso do Sul. As leis estaduais sobre APP apresentam texto muito próximos a Lei n ${ }^{\circ}$ 12. 651 (BRASIL, 2012a), mas sem referência direta a Vereda.

De forma geral, o estado de Minas Gerais, dentre os analisados, é o que há mais tempo busca a proteção das Veredas, bem como possui o maior número de leis a mencionar essa fitofisionomia, e o único a tentar uma conceituação de diferentes tipos de Veredas. Entretanto, atualmente regrediu no sentido da proteção desse ambiente e passou a ter legislação muito semelhante à Legislação Federal. O estado de Goiás já efetuou várias tentativas de preservação das Veredas, mas atualmente segue em sua legislação, redação muito próxima ao que existe em nível federal. Em Tocantins, há uma única lei que trata da proteção das Veredas, mas de forma muito mais relacionada à possibilidade de uso do que a real proteção. O Distrito Federal, embora 
cite Veredas em uma lei sobre criação de parques, não possui lei que determine sua proteção. Ceará e Bahia têm leis que versam sobre Veredas, mas de forma incipiente para a garantia de uma proteção efetiva. Maranhão e Piauí só citam o buriti, sem qualquer referência às Veredas. Mato Grosso cita Veredas como APP, mas atualmente não possui qualquer lei em vigor com tal referência. Em Rondônia, a única referência sobre Veredas ocorre em lei sobre a atividade de piscicultura, mas que não visa qualquer proteção à esses ecossistemas, mas sim disciplina a atividade econômica. Em São Paulo, embora exista lei que cite Veredas, também não há legislação específica sobre sua proteção.

Diante da análise da legislação ambiental de todas as Unidades da Federação com ocorrência de Cerrado em seu território, verificamos que inexiste marco legal mais restritivo ao uso de Veredas ou capaz de propiciar proteção efetiva. Os poucos estados com leis a mencionar diretamente essa fisionomia como APP, o fazem muito próximo do determinado na Legislação Federal, portanto, compartilham dos mesmos problemas.

\section{CONSIDERAÇÕES FINAIS}

Esse estudo contribuiu com revisões na legislação ambiental brasileira e conhecimento sobre as principais características das Veredas, bem como definição mais precisa e que considere os diversos aspectos físicos e biológicos, a fim de garantir maior proteção a essa importante fitofisionomia do Cerrado. Tendo em vista que muitas de suas definições, inclusive na atual legislação, são imprecisas e incapazes de abranger todos os tipos existentes de Vereda.

Consideramos que a homologação da Lei Federal $n^{\circ} 12.651$ flexibilizou as questões relacionadas à proteção das Veredas. Portanto, sugerimos discussões para uma revisão do conceito de Vereda adotado, de modo que suas peculiaridades sejam abrangidas. Também recomendamos a correção do artigo $4^{\circ}$, alínea XII, para que não existam dúvidas da proteção direta das Veredas e de sua faixa marginal. Outra alteração necessária é na forma como se definem seus limites. Ou seja, o ideal seria pela presença de solo hidromórfico, e não utilizar a nomenclatura de solo permanentemente brejoso e encharcado.

As leis estaduais específicas para esta fitofisionomia, tem como alicerce a supracitada Lei Federal. Portanto, como ocorreu na legislação federal, houve também retrocessos em nível estadual quanto à proteção das Veredas. Frente ao processo de ocupação do Cerrado, com diversos problemas ambientais e forte pressão sobre seus ecossistemas, a legislação ambiental se mostra frágil e demonstra incapacidade em garantir proteção mínima para os mesmos e, em 
especial às AU e às Veredas. Sendo assim, são necessárias alterações urgentes visando maior eficácia na proteção dessa importantes e ameaçada fisionomia do Cerrado brasileiro.

\section{REFERÊNCIAS}

ANJOS, L. H. C. et al. Matéria orgânica e pedogênese. In: SANTOS, G. de A.; CAMARGO, F. A. de O. (ed.). Fundamentos da matéria orgânica do solo: ecossistemas tropicais e subtropicais. 2. ed. Porto Alegre: Metrópole, 2008. p. 66-85.

ANTUNES, P. de B. Regime jurídico dos Sítios Ramsar no Brasil. Blog GEN Jurídico. São Paulo, 29 nov. 2019. Disponível em: http://genjuridico.com.br/2019/11/29/regime-juridico-sitios-ramsarbrasil/. Acesso em: 11 maio 2020.

ARAÚJO, G. M. et al. Composição florística de Veredas no município de Uberlândia, MG. Rev Bras Bot, São Paulo, v. 25, n. 4, p.475-493, 2002.

AULETE, C. Dicionário contemporâneo da língua portuguesa. 5. ed. Rio de Janeiro: Delta, 1970.

BAHIA [Constituição (1989)]. Constituição do Estado da Bahia - 1989. Salvador: EGBA, 1999. Disponível em: http://www2.senado.leg.br/bdsf/handle/id/70433. Acesso em: 31 abr. 2018.

. Lei $\mathrm{n}^{\circ}$ 10.431, de 20 de dezembro de 2006. Altera a Lei $\mathrm{n}^{\circ} 10.431$, de 20 de dezembro de 2006, a Lei no 11.612, de 08 de outubro de 2009 e a Lei no 11.051, de 06 de junho de 2008. Disponível em: https://www.legisweb.com.br/legislacao/?id=121083. Acesso em: 31 maio 2018.

. Lei $\mathbf{n}^{\circ}$ 12.377, de 28 de dezembro de 2011. Altera a Lei $\mathrm{n}^{\circ} 10.431$, de 20 de dezembro de 2006, a Lei $n^{\circ} 11.612$, de 08 de outubro de 2009 e a Lei $n^{\circ} 11.051$, de 06 de junho de 2008. Disponível em: http://www.seia.ba.gov.br/legislacao-ambiental/leis/lei-n-12377-de-28-de-dezembro-de-2011. Acesso em: 30 maio 2018.

. Lei no 6.569, de 17 de janeiro de 1994. Dispõe sobre a Política Florestal no Estado da Bahia e dá outras providências. Disponível em: https://documentacao.socioambiental.org/documentos/M3D00027.pdf. Acesso em: 30 maio 2018.

BARBOSA, A. S. Cerrado biodiversidade e pluralidade. Flash UCG: notícias da Universidade Católica de Goiás. 2008. Disponível em: http://www2.ucg.br/flash/cerradoA.html. Acesso em: 15 jan. 2008.

BARBOSA, G. S. Uso de atributos do solo na identificação de limites para preservação de Veredas no Mato Grosso do Sul. 2016. 72 f. Dissertação (Mestrado em Agronomia) - Faculdade de Engenharia de Ilhas Solteira, Universidade Estadual Paulista, Ilha Solteira, 2016.

BOAVENTURA, R. S. Contribuição aos estudos sobre a evolução das Veredas. In: ENCONTRO NACIONAL DE GEÓGRAFOS, 3., 1978, Fortaleza. Comunicações [...]. Fortaleza: [s. n.], 1978. p. 13-17.

. Preservação das Veredas: síntese. In: ENCONTRO LATINO AMERICANO RELAÇÃO SER HUMANO-AMBIENTE, 2., Anais [...]. Belo Horizonte: FUMEC, 1988. p. 109-118.

BRANDÃO, M.; CARVALHO, P. G. S.; BARUQUI, F. M. Veredas: uma abordagem integrada. Daphne, Belo Horizonte, v. 1, n. 3, p. 5-8, 1991. 
BRASIL. Conselho Nacional do Meio Ambiente. Resolução no 004, de 18 de setembro de 1985. Dispõe sobre reservas ecológicas. Disponível http://www.mma.gov.br/port/conama/legiano.cfm?. Acesso em: 18 nov. 2013.

. Conselho Nacional do Meio Ambiente. Resolução n 303, de 20 de março de 2002. Dispõe sobre Parâmetros, Definições e Limites de Áreas de Preservação Permanente. Disponível em: http://www.mma.gov.br/port/conama/legiano.cfm?. Acesso em: 18 mar. 2013.

. Conselho Nacional do Meio Ambiente. Resolução n 369, de 28 de março de 2006. Dispõe sobre os casos excepcionais, de utilidade pública, interesse social ou baixo impacto ambiental, que possibilitam a intervenção ou supressão de vegetação em Área de Preservação Permanente-APP. Disponível em: http://www.mma.gov.br/port/conama/legiabre.cfm?. Acesso em: 31 maio 2018.

. Constituição (1988). Constituição da República Federativa do Brasil de 1988. Brasília: Presidência da República, 05 out. 1988. Disponível em: http://www.planalto.gov.br/ccivil_03/constituicao/constituicao.htm. Acesso em: 11 maio 2020.

. Decreto n 1.905 , de 16 de maio de 1996. Promulga a Convenção sobre Zonas Úmidas de Importância Internacional, especialmente como Habitat de Aves Aquáticas, conhecida como Convenção de Ramsar, de 02 de fevereiro de 1971. Brasília, 16 maio 1996. Disponível em: http://www.planalto.gov.br/ccivil_03/decreto/1996/D1905.htm. Acesso em: 06 jun. 2018.

. Lei n⿳9.985, de 18 de julho de 2000. Regulamenta o art. 225, § 1丷ㅜ incisos I, II, III e VII da Constituição Federal, institui o Sistema Nacional de Unidades de Conservação da Natureza e dá outras providências. Brasília, 18 jul. 2000. Disponível em: http://www.planalto.gov.br/ccivil_03/LEIS/L9985.htm. Acesso em: 12 maio 2020.

. Lei $n^{\circ} 12.651$, de 25 de maio de 2012. Dispõe sobre a proteção da vegetação nativa; altera as Leis $\mathrm{n}^{\circ}$ 6.938, de 31 de agosto de 1981, 9.393, de 19 de dezembro de 1996, e 11.428, de 22 de dezembro de 2006; revoga as Leis $n^{\circ} 4.771$, de 15 de setembro de 1965, e 7.754, de 14 de abril de 1989, e a Medida Provisória n n $^{\text {2.166-67, de }} 24$ de agosto de 2001; e dá outras providências. Diário Oficial da República Federativa do Brasil. Brasília, 28 maio 2012a. Disponível em: http://www.planalto.gov.br/ccivil_03/_Ato2011-2014/2012/L12651.htm. Acesso em: 3 out. 2014.

Lei $\mathbf{n}^{0}$ 12.727, de 17 de outubro de 2012. Altera a Lei $\mathrm{n}^{\circ} 12.651$, de 25 de maio de 2012, altera as Leis $n^{\circ} 6.938$, de 31 de agosto de 1981, 9.393, de 19 de dezembro de 1996, e 11.428, de 22 de dezembro de 2006. Diário Oficial da República Federativa do Brasil. Brasília, 18 out. 2012b. Disponível em: http://www.planalto.gov.br/ccivil_03/_Lei/L12727.htm. Acesso em: 30 maio 2018.

. Ministério do Meio Ambiente. Áreas Úmidas - Convenção de Ramsar. 2018. Disponível em: http://www.mma.gov.br/biodiversidade/biodiversidade-aquatica/zonasumidas-convencao-deramsar. Acesso em: 06 abr. 2018.

BUENO, F. S. Grande dicionário etimológico-prosódico da língua portuguesa. Santos: Editora Brasília Limitada, 1974. v. 8.

CARVALHO, P. G. S. As Veredas e sua importância no domínio dos cerrados. Inf Agropec, Belo Horizonte, v. 15, n. 168, p. 47-54, 1991.

CASTRO, J. P. C. As Veredas e sua proteção jurídica. Anal Conjunt, Belo Horizonte, v. 10, n. 5-6, p. 321-333, mai./jun., 1980. 
CEARÁ. Decreto $\mathbf{n}^{\mathbf{0}} \mathbf{2 4 . 2 2 1}$, de 12 de setembro de 1996. Disponível em: http://antigo.semace.ce.gov.br/integracao/biblioteca/legislacao/conteudo_legislacao.asp?cd=63.

Acesso em: 31 maio 2018.

. Lei $n^{\circ} 12.488$ de 13 de setembro de 1995. Dispõe sobre a Política Florestal do Ceará e dá outras providências. Disponível em: https://www.legisweb.com.br/legislacao/?id=277634. Acesso em: 31 maio 2018.

CUNHA, A. G. da. Dicionário etimológico nova fronteira da língua portuguesa. 2. ed. Rio de Janeiro: Nova Fronteira, 1989.

CUNHA, C. N.; PIEDADE, M. T. F.; JUNK, W. F. Classificação e delineamento das áreas úmidas brasileiras e de seus macrohabitats. Cuiabá: Instituto Nacional de Ciência e Tecnologia em Áreas Úmidas (INAU)/EdUFMT, 2015.

DE-CAMPOS, A. B. Spatial distribution of tropical wetlands in Central Brazil as influenced by geological and geomorphological settings. J S Am Earth Sci, [s. l.], v. 46, p. 161-169, 2013.

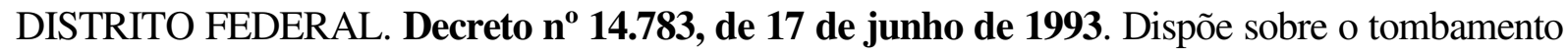
de espécies arbóreo-arbustivas, e dá outras providências. Disponível em: http://hmjbb.ibict.br/handle/1/577. Acesso em: 31 abr. 2018.

. Decreto n' 38.849, de 08 de fevereiro de 2018. Altera o Decreto 14.783, de 17 de junho de 1993. Disponível em: http://www.tc.df.gov.br/SINJ/Norma/5fb49f68a5f841e1830ddc07696b955f/Decreto_38849_08_02 _2018.html. Acesso em: 31 maio 2018.

. Lei Complementar $\mathbf{n}^{\circ}$ 265, de dezembro de 1999. Dispõe sobre a criação de Parques Ecológicos e de Uso Múltiplo no Distrito Federal. Disponível em: http://www.sema.df.gov.br/wpconteudo/uploads/2017/09/Lei-Complementar-2\%BA-265-de-1999.pdf. Acesso em: 31 maio 2018.

FERNANDES, P. A. F.; PESSÔA, V. L. S. O Cerrado e suas atividades impactantes: uma leitura sobre o garimpo, a mineração e a agricultura mecanizada. Observatorium, Uberlândia, v. 3, n. 7, p. 19-37, out. 2011.

FERREIRA, I. M. Aspectos paisagísticos do Cerrado: degradação da paisagem de Vereda. In: ENCONTRO DE GEOGRÁFOS DA AMÉRICA LATINA - EGAL, 12., 2009, Montivideo (Uruguai). Anais do Encontro de Geográfos da América Latina- EGAL. Montivideo: [s. n.], 2009. p. 1-13.

. Modelos geomorfológicos das Veredas no ambiente de Cerrado. Esp Rev, Catalão, v. 7/8, n. 1, p. 7-16, jan/dez. 2005/2006.

. O afogar das Veredas: uma análise comparativa espacial e temporal das Veredas do Chapadão de Catalão (GO). 2003. 242 f. Tese (Doutorado em Geografia) - Instituto de Geociências e Ciências Exatas, Universidade Estadual Paulista, Rio Claro, 2003.

. Paisagens do Cerrado: aspectos conceituais sobre Vereda. In: Simpósio Nacional sobre o Cerrado, 9., 2008, Brasília. Anais [...]. Brasília: Embrapa Cerrados, 2008.

GOIÁS. Lei n. ${ }^{\circ}$ 12.596, de 14 de Março de 1995. Lei Florestal do Estado de Goiás. Goiânia: FEMAGO/SEMARH, 1995.

. Lei $n^{0}$ 18.104, de 18 de junho de 2013. Dispõe sobre a proteção da vegetação nativa, institui a nova Política Florestal do Estado de Goiás e dá outras providências. Disponível em: 
http://www.gabinetecivil.goias.gov.br/leis_ordinarias/2013/lei_18104.htm. Acesso em: 31 maio 2018.

GRANZIERA, M. L. M.; ADAME, A.; GALLO, G. N. Direito ambiental internacional Conservação dos espaços e da biodiversidade - Convenção Ramsar. In: CONGRESSO NACIONAL DO CONPEDI, 15., 2006, Manaus. Anais do XV Congresso Nacional do CONPEDI. Manaus, CONPEDI, 2006. p. 1-21.

HUNG, M. N. W. B.; MARANGON, F. H. S.; SANTOS, I. dos. Comparação entre o Índice Topográfico e o Tasseled Cap wetness na estimativa da umidade do solo na bacia hidrográfica do Rio Corredeiras - SC. In: SIMPÓSIO BRASILEIRO DE GEOGRAFIA FÍSICA APLICADA, 17., 2017, Campinas. Os desafios da Geografia física na fronteira do conhecimento. Campinas, [s. n.], 2017. p. 442-453.

JUNK, W. J. et al. Definição e classificação das Áreas Úmidas (AUs) brasileiras: base científica para uma nova política de proteção e manejo sustentável. In: CUNHA, C. N. (org.); PIEDADE, M. T. F.; JUNK, W. J. (org.). Classificação e delineamento das Áreas Úmidas brasileiras e de seus macrohabitats. Cuiabá: INCT-INAU; EdUFMT, 2015. p. 13-76.

JUNK W. J.; PIEDADE, M. T. F.; CANDOTTI, E. Água no Brasil: excesso, escassez e problemas crescentes. Cienc Hoje, [s. l.], v. 315, n. 53, p. 52-53, jul. 2014.

MARANHÃO. Lei estadual no 5.405, de 05 de abril de 1992. Institui o Código de Proteção de Meio Ambiente e dispõe sobre o Sistema Estadual de Meio Ambiente e o uso adequado dos recursos naturais do Estado do Maranhão. Disponível em: http://www.stc.ma.gov.br/legisladocumento/?id=1823. Acesso em: 31 maio 2018.

MARTINS, R. A. et al. O (des) caminho das águas: alteração no subsistema de Vereda provocado por reservatório destinado ao abastecimento de pivô central. Cam Geogr, [s. l.], v. 18, n. 61, p. 83102, mar. 2017.

MATO GROSSO. Lei Complementar no 38, de 21 de novembro de 1995. Dispõe sobre o Código Estadual do Meio Ambiente e dá outras providências Disponível em: https://www.legisweb.com.br/legislacao/?id=131145. Acesso em: 31 maio 2018.

. Lei Complementar $n^{0}$ 412, de 13 de dezembro de 2010. Dispõe sobre alterações na Lei Complementar $\mathrm{n}^{\circ} 38$, de 21 de novembro de 1995, na Lei Complementar $\mathrm{n}^{\circ} 232$, de 21 de dezembro de 2005, Lei Complementar $n^{\circ}$ 233, de 21 de dezembro de 2005, a Lei Complementar no 343, de 24 de dezembro de 2008 e dá outras providências. Disponível em: https://www.al.mt.gov.br/legislacao/6352/visualizar. Acesso em: 31 maio 2018.

Lei Complementar $n^{0}$ 595, de 10 de agosto de 2017. Altera dispositivo da Lei Complementar $\mathrm{n}^{\mathbf{0}} \quad 38$, de 21 de novembro de 1995. Disponível em: https://www.legisweb.com.br/legislacao/?id=347559. Acesso em: 31 maio 2018.

MELO, D. R. As Veredas nos planaltos do Noroeste Mineiro: caracterizações pedológicas e os aspectos morfológicos e evolutivos. 1992. 219 f. Dissertação (Mestrado em Geografia) - Instituto de Geociências e Ciências Exatas, Universidade Estadual Paulista, Rio Claro, 1992.

Evolução das Veredas sob impactos ambientais nos geossistemas Planaltos de Buritizeiros/MG. 2008. 341 f. Tese (Doutorado em Geografia) - Instituto de Geociências, Universidade Federal de Minas Gerais, Belo Horizonte, 2008. 
MINAS GERAIS. Constituição do Estado de Minas Gerais de 1989. 19. ed. Belo Horizonte: Assembleia Legislativa do Estado de Minas Gerais, 2018. Disponível em: https://www.almg.gov.br/consulte/legislacao/completa/completa-novamin.html?tipo=CON\&num=1989\&ano=1989. Acesso em: 31 maio 2018.

. Lei n⿳0 14.309 , de 19 de junho de 2002. Dispõe sobre as políticas florestais e de proteção à biodiversidade no Estado. Disponível em: http://www.ief.mg.gov.br/images/stories/conselho_administracao/menu/lei\%2014309\%202002.pdf. Acesso em: 31 maio 2018.

. Lei no 20.922, de 16 de outubro de 2013. Dispõe sobre as políticas florestal e de proteção à biodiversidade no Estado. Disponível em: http://www.siam.mg.gov.br/sla/download.pdf?idNorma=30375. Acesso em: 31 maio 2018.

. Lei $\mathbf{n}^{\circ}$ 9.375, de 12 de dezembro de 1986. Declara de interesse comum e de preservação permanente os ecossistemas das Veredas no Estado de Minas Gerais. Disponível em: http://www.siam.mg.gov.br/sla/download.pdf?idNorma=2196. Acesso em: 31 maio 2018.

. Lei $n^{\circ}$ 9.682, de 12 de outubro de 1988. Altera a ementa e o artigo $1^{\circ}$ da Lei $n^{\circ} 9.375$, de 12 de dezembro de 1986, que declara de interesse comum e de preservação permanente os ecossistemas das Veredas do vale do Rio São Francisco e dá outras providências. Disponível em: http://www.siam.mg.gov.br/sla/download.pdf?idNorma=2215. Acesso em: 31 maio 2018.

MINISTÉRIO PÚBLICO DE GOIÁS. Análise das principais mudanças que a lei federal $\mathbf{n}^{\mathbf{0}}$ 12.651/12, de 25 de maio (com as inserções advindas pela Medida provisória n 571/12, de 25 de maio, e pela Lei Federal $\mathrm{n}^{\mathbf{0}} \mathbf{1 2 . 7 2 7 / 1 2}$, de 17 de outubro), trouxe ao ordenamento jurídico ambiental. Goiânia: $\quad[s . \quad n$. $], \quad 2012 . \quad$ Disponível http://www.mpgo.mp.br/portal/system/resources/W1siZiIsIjIwM.pdf. Acesso em: 18 dez. 2015.

NASCIMENTO, P. C. do et al. Caracterização, classificação e gênese de solos hidromórficos em regiões litorâneas do Estado do Espírito Santo. Científica, Jaboticabal, v. 41, n. 1, p.82-93, 2013.

NEUE, H. U. et al. Carbon in tropical wetlands. Geoderma, [s. l.], v. 79, p. 163-185, abr. 1997.

PIAUÍ. Lei no 3.888, de 26 de setembro de 1983. Proíbe a derrubada de palmáceas e árvores, que especifica, e dá outras providências. Disponível em: https://www.leisdopiaui.com/singlepost/2017/02/26/lei-38. Acesso em: 31 maio 2018.

QUEIROZ, M. L. Nascentes, Veredas e áreas úmidas: revisão conceitual e metodologia de caracterização e determinação, estudo de caso na Estação Ecológica de Águas Emendadas - Distrito Federal. 2015. 161 f. Dissertação (Mestrado em Hidrogeologia) - Universidade de Brasília, Brasília, 2015.

RAMOS, M. V. V. et al. Veredas do Triângulo Mineiro: solos, água e uso. Cienc Agrotec, [s. l.], v. 30, p. 283-293, 2006.

RIBEIRO, J. F.; WALTER, B. M. T. Fitofisionomias do_bioma Cerrado. In: SANO, S. M. (ed.); ALMEIDA, S. P. de. (ed.); RIBEIRO, J. F. (ed.). Cerrado: ecologia e flora. Brasília: Embrapa Informação Tecnológica, 2008. p. 153-212.

RONDÔNIA. Lei $\mathbf{n}^{\mathbf{0}}$ 1.861, de 10 de janeiro de 2008. Dispõe, define e disciplina a Piscicultura no Estado de Rondônia, e dá outras providências. Disponível em: https://sapl.al.ro.leg.br/consultas/norma_juridica/norma_juridica_mostrar_proc?cod_norma=3887. Acesso em: 31 maio 20118. 
ROSOLEN, V. et al. Vereda and Murundu wetlands and changes in Brazilian environmental laws: challenges to conservation. Wetl Ecol Manag, [s. l.], v. 23, p. 285-292, 2015.

SANTOS, E. V. dos et al. Visão ambiental do subsistema vereda na Microrregião de Catalão (GO). Esp Rev, Catalão, v. 15, n. 2, p. 141-162, jul/dez, 2013.

SANTOS, E. V. dos; GULHERME, F. A. G. Áreas úmidas no Brasil e no mundo: um enfoque no Cerrado brasileiro e nas Veredas. In: MARTINS, A. P. M. (org.); CABRAL, J. B. P. (org.). Reflexões geográficas no Cerrado brasileiro. Curitiba: CRV, 2019. p. 63-82.

SÃO PAULO. Lei n⿳ 15.684, de 14 de janeiro de 2015. Dispõe sobre o Programa de Regularização Ambiental - PRA das propriedades e imóveis rurais, criado pela Lei Federal no 12.651, de 2012 e sobre a aplicação da Lei Complementar Federal n 140, de 2011, no âmbito do Estado de São Paulo. Disponível em: https://www.al.sp.gov.br/repositorio/legislacao/lei/2015/lei-15684-14.01.2015.html. Acesso em: 31 maio 2018.

SILVA NETO, L. de F. Pedogênese e matéria orgânica de solos hidromórficos da região metropolitana de Porto Alegre. 2010. 117 f. Tese (Doutorado em Ciência do Solo) - Faculdade de Agronomia, Universidade Federal do Rio Grande do Sul, Porto Alegre, 2010.

SOUZA, J. dos R.; ROSOLEN, V. S. A conversão de áreas úmidas em usos agrícolas na bacia hidrográfica do Beija-Flor - MG: análise do carbono total e impactos ambientais em murundus. For Amb A Paul, [s. l.], v. 10, n. 2, p. 133-149, 2014.

TOCANTINS. Lei $\mathbf{n}^{\mathbf{0}}$ 1.939, de 24 de junho de 2008. Dispõe sobre os casos excepcionais de utilidade pública, interesse social ou baixo impacto ambiental que possibilitam a intervenção ou supressão de vegetação em Área de Preservação Permanente - APP, e adota outras providências. Disponível em: https://central3.to.gov.br/arquivo/345115/. Acesso em: 31 maio 2018.

VENANCIO, D. L.; KURTZ, F. C. Evolução da legislação sobre o Meio Ambiente e o processo de valoração econômica da água no Brasil. Ambiência, Guarapuava v. 5, n. 1, p. 155-171, jan./abr. 2009. 